\title{
People-Space Analytics: Case Study of Work Dynamics
}

\author{
AMIN MOJTAHEDI \\ HGA Architects \& Engineers / University of Wisconsin-Milwaukee, School of Architecture \& Urban Planning \\ SO-YEON YOON \\ Cornell University, College of Human Ecology \\ TAHEREH A. HOSSEINI \\ University of Wisconsin-Milwaukee, College of Engineering \& Applied Science \\ DIEGO H. DIAZ MARTINEZ \\ Florida State University, Department of Mathematics
}

To deliver an innovative design, architects often need to innovate in the ways they empathize with and understand the user. In his 1994 essay, the American Pragmatist philosopher Richard Rorty writes that "one should stop worrying about whether what one believes is well-grounded and start worrying about whether one has been imaginative enough to think up interesting alternatives to one's present beliefs"1. This study, primarily, explores an interdisciplinary approach in which data collection, analysis, and interpretation are used as drivers of inspiration as well as tools of validation. A combination of tools and techniques labeled as people-space analytics was used to investigate the socio-spatial dynamics of work in the workplace of a national architecture firm. The results were later interpreted from a certain lens in the community of practice theory. A secondary goal of this research project is to study how workplace's spatial configuration and key people and places are involved in organizational learning and knowledge practices. Therefore, a set of metrics and measures were used to interpret different employees' recurrent patterns of communication and flow of information between people from different social networks in a spatial context.

\section{INTRODUCTION}

Workplace is a complex ecology comprised of various correlational relationships between people, spaces, objects and artifacts, practices, technology, and information. These correlational relationships are important because they are often directly tied to important workplace outcomes such as recruitment and retention, business performance and productivity, efficient allocation of resources and spaces, brand and culture, return on real estate investment, work-life balance, and strategizing for knowledge practices among others. That said, decoding this ecology in its entirety is neither easy nor necessary. A useful investigation could reveal meaningful constellations within this ecology (Figure 1). A typical workplace constellation might include a certain team's work-dynamics and its generational make-up,

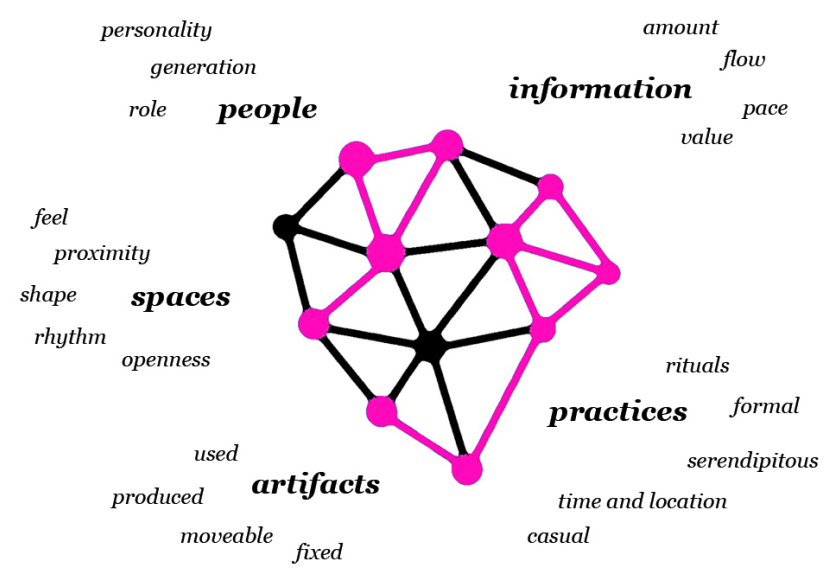

Figure 1: Meaningful constellations within the workplace ecology

configuration of spaces they use, and the variety of moveable furniture within those spaces. But almost similar to the tales of zodiac in the sky, a meaningful constellation in the workplace should tell us a compelling story. Yet before getting into the details of this study's narrative, we will first explore the theoretical lens, techniques, and measures used to gather and make sense of the data.

\section{COMMUNITY OF PRACTICE (COP) THEORY}

The community of practice perspective is largely conceptualized and explained by the social learning theorist Étienne Wenger ${ }^{2,3,4,5,6,7}$. Wenger explains that his theory has its roots in the attempt to develop accounts of the social nature of human learning inspired by anthropology and social theory reflected in Lave's conceptualization of cognition in practice ${ }^{8}$, Bourdieu's habitus/field theory ${ }^{9}$, Giddens' structuration theory ${ }^{10}$, Foucaultian concept of power ${ }^{11}$, and Vygostsky's zone of proximal development ${ }^{12}$. CoP has also been widely referred to as a key component of a knowledge strategy in organizations ${ }^{3,13,14,15,16}$

Since the early 1990s, the concept of CoP has been extensively used as a theoretical construct, a practical learning and knowledge strategy, and an effective managerial tool to address issues of individual 
learning and organizational development across multiple social science disciplines and professional fields ${ }^{17,18,19}$. Therefore, there have been various interpretations of the concept. In their brief introduction to CoPs, Wenger and Trayner ${ }^{20}$ define the concept and address some of the assertions about it:

"Communities of practice are formed by people who engage in a process of collective learning in a shared domain of human endeavor... [they] are groups of people who share a concern or a passion for something they do and learn how to do it better as they interact regularly ... the role of CoPs is [not only] to share knowledge ... [but also] to innovate and solve problems."

In workplaces, a CoP grants different levels of participation to learners and legitimizes persons' positions on the periphery of practice. In other words, it enculturates learners ${ }^{21}$ and encourages them to become insiders by learning to function in the community ${ }^{13}$ and becoming more competent members.

\section{PERIPHERY, BOUNDARY, AND BOUNDARY MECHANISMS}

Wenger tends to use geographical metaphors in explaining his theory, possibly more than any other theorist of social learning and knowing. However, one needs to be mindful of the fact that his application of these terms is not literal and the direct extension and generalization of them to the material realm will most probably lead to misunderstanding. Consequently, examining Wenger's theory in the context of an architectural academic effort requires additional sensitivity towards the theory's terminology. Thus in this and next sections, differences and similarities between several important terms in the context of CoP perspective are explained. These terms include periphery, peripheral participation, boundary, boundary object, and brokering.

According to the CoP theory, as novices initially join communities of practice, they start learning at the periphery. This mode of learning happens as newcomers participate in low intensity and low-risk yet productive and necessary activities. For their learning experience to be authentic, peripheral participants are also granted legitimate access to resources of the community including its members and shared repertoire in use. Therefore, as the newcomer becomes acculturated to the norms and practices of the community, she becomes more knowledgeable, develops mastery identity, and eventually turns into an old-timer. Of course, peripheral members take responsibility of certain tasks that are necessary for the functioning of the community. However, as they move from peripheral to more active and core participation in the community, become more central, and construct new identities, they also naturally engage in a process of negotiating the identity of the community of practice. The constant negotiation of meaning contributes to the community's longevity, evolution, or paradigm shift as long as it keeps recruiting new members, and, of course, its core practices are not disrupted by other communities in the landscape.

While peripheral participation has an inward tendency and is concerned about its host community of practice, boundary turns the focus outward and encourages the community to consider the broader landscape of practice. Wenger ${ }^{7}$ explains that boundaries are the inevitable consequence of learning as the production of practice. They are not, necessarily, created because of participants' intentional desire to exclude outsiders. It, in fact, is the shared history of learning amongst members and their situated knowledge about the domain that distinguishes them from those who are not involved in the CoP:

"Practices are like minicultures, and even common words and objects are not guaranteed to have continuity of meaning across a boundary. At the same time, boundaries can be as much a source of learning as the core of a practice. The meetings of perspectives can be rich in new insights and radical innovations. Still such new insights are not guaranteed, and the likelihood of irrelevance makes engagement at the boundaries a potential waste of time and effort. Indeed, competence in not well defined at boundaries. This means that the innovation potential is greater, but so is the risk of wasting time or getting lost."

Various boundary mechanisms can be the source of continuities and discontinuities across different communities of practice. Two types of boundary mechanisms that encourage connection between communities are boundary objects and brokering. Boundary objects are artifacts, documents, terms, concepts, and often forms of reification around which communities of practice can organize their interconnections whereas brokering includes connections provided by people who can introduce elements of one practice into another ${ }^{4}$. This role creates connections between people from different organizations, cultures, sectors or localities, brokering and translating varying perspectives, and facilitating the application of ways seeing and doing across different domain ${ }^{22}$. Wenger ${ }^{4}$ writes that most of us in occasions exhibit brokering behavior. Yet, there seem to be individuals who thrive on being brokers:

"They love to create connections and engage in 'import-export," and so would rather stay at the boundaries of many practices than move to the core of any one practice. The job of brokering is complex. It involves processes of translation, coordination, and alignment between perspectives ... Brokering often entails ambivalent relations of multimembership."

In this study we focused on brokering as a type of boundary mechanism or activity whose conveyor, as opposed to a boundary object, is the individual person.

\section{METHOD}

According to several researchers including Wenger himself, there is validity in using social network analysis (SNA) methods and techniques in understanding CoPs. In 'communities of practice and social learning systems' Wenger ${ }^{7}$ writes that the concept of community emphasizes identity while network focuses on connectivity. Yet he also argues that the two usually coexist and CoPs are certainly networks in the sense that they involve connections among members. There are examples of studies such as Marsico et al. ${ }^{23}$ and Cross et al. ${ }^{24}$ which use SNA methods and metrics to map CoPs. 


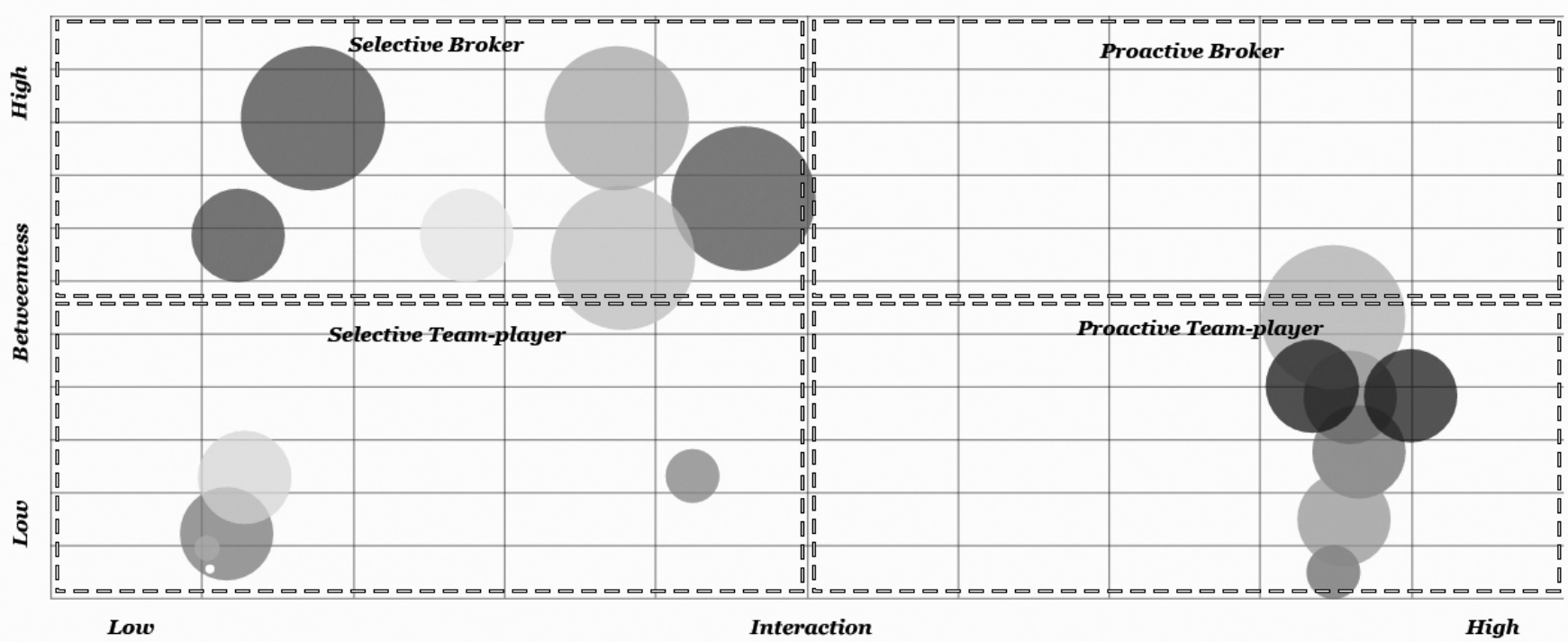

Figure 2: Boundary activity $=\mathrm{f}$ (betweenness, weight, degree)

Each bubble represents a person and the size represents the node's degree.

People-space analytics is a term that we use in this study to describe an approach towards capturing and analyzing social dynamics in the physical space for providing data-driven accounts about how organizations use the physical space. People-space analytics toolbox employs different technologies, techniques, and theories - from tracking social interaction and location to incorporating SNA and CoP perspective into physical space occupancy data.

People-space analytics uses various knowledge and learning theories to make sense of the collected information, yet on the methodological level it draws inspirations from the work of Human Dynamics Lab at MIT Media Laboratories. This methodology is captured in Alex Sandy Pentland' ${ }^{25}$ definition of social physics:

"Social physics is a quantitative social science that describes reliable, mathematical connections between information and idea flow on the one hand and people's behavior on the other. Social physics helps us understand how ideas flow from person to person through the mechanism of social learning and how this flow of ideas ends up shaping the norms, productivity, and creative output of our companies, cities, and societies."

Ben Waber, a visiting scientist at the MIT Media Lab and the author of 'people analytics: how social sensing technology will transform business and what it tells us about the future of work', is also a proponent of data-driven strategies for building better organizations. Although Waber's work is mostly focused on the social side of organizations, he has acknowledged the significance of physical and spatial qualities of workplaces in several occasions ${ }^{26,27}$ :

"Companies should always look to physical space as a key part of their toolbox for changing patterns of collaboration and behavior. The actual layout of the office, the type of furniture, and the decision to let employees work remotely all have a profound impact on both companies' and individuals' success. Distance is not dead. If anything, it's more central to our lives than ever."

Work-persona questionnaire was one of the surveys launched in this study. The multiple choice questionnaire asked participants to choose three personas that they sympathize with out of 10 personas described in 'the ten faces of innovation' by IDEO's Tom Kelley and Jonathan Littman ${ }^{28}$. Observation and note-taking were also implemented.

\section{FINDINGS}

To provide structure for a more detailed exploration of boundary mechanisms in the workplace ecology, we framed our work around three fundamental research questions pertaining to these mechanisms in the physical space: (1) How can we describe boundary mechanisms as SNA-related constructs in space? (2) How can we map them relative to space? (3) How can we evaluate them relative to space? Certain measures and metrics in SNA help us answer the first question. For example, betweenness centrality, as a measure for quantifying the control of a human on the communication between two other humans in a social network ${ }^{29}$, is indicative of brokering or peripheral behavior. As a matter of fact, Pentland ${ }^{30}$ also uses this measure to explain how often people go exploring outside their team and bring new ideas and information back.

So a boundary activity is a function of betweenness centrality, but is it not also a function of amount and number of interactions? Waber et al. ${ }^{31,32}$ and Wu et al. ${ }^{33}$ explain that there is a strong correlation between interaction and performance, but their definition of performance does not take betweenness centrality into account. That said, a significant number of workplace designers, especially proponents of drawing inspirations from urban life to create better work spaces - Frank Duffy, Clive Wilkinson, Herman Hertzberger, among many others - , seem to indicate that strategies which help increase interactions will eventually result in more chance encounters. For example, Duffy ${ }^{34}$ believes what 

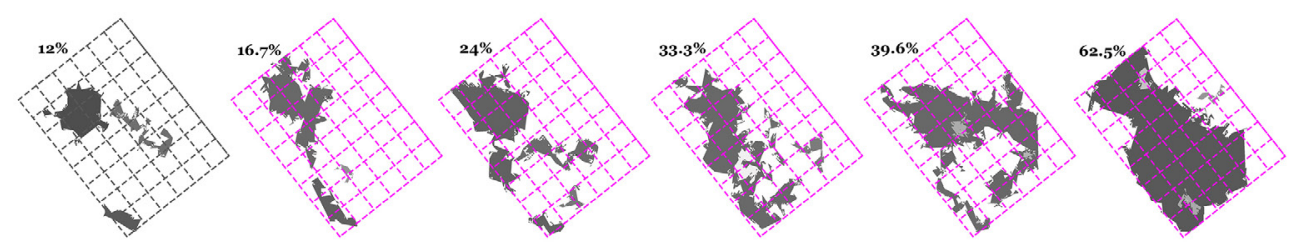

Proactive Team-player (Avg 21.9\%)
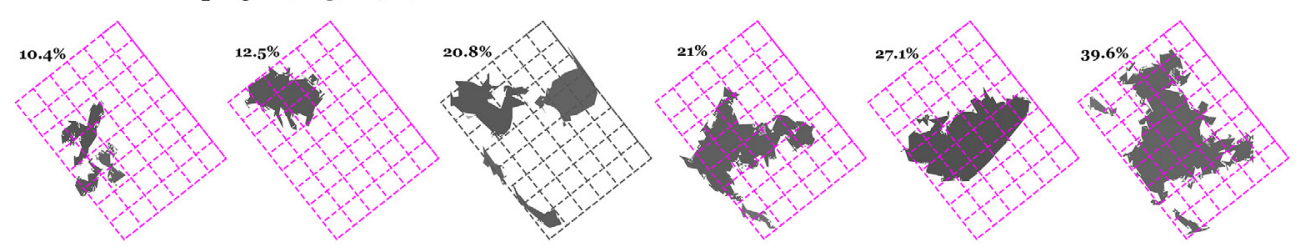

Selective Team-player (Avg 16\%)
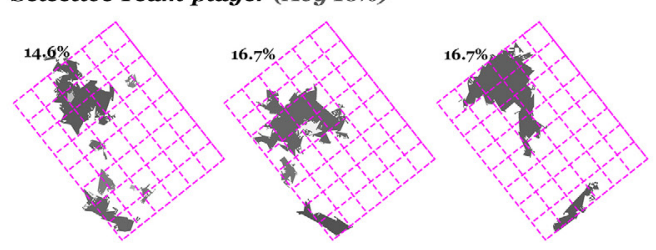

Figure 3: Space-use patterns accorss selective brokers and team-players

constitutes for the success, productivity, and congeniality of the city social life is the density of overlap among various social networks.

Similarly, several of our study participants thought that there is a logical connection between the two. For example, one study participant said: "More interaction is definitely good. You'll eventually talk to people with higher probability of relevance." Another participant believed: "You want for more people to talk to each other. That's how new ideas are born." In other words, more exposure through interaction will increase the chance for activating boundary mechanisms. Considering all this, the definition of boundary activity in our study takes betweenness centrality, the amount of interactions, and the number of people with whom interaction has happened into account: Boundary activity $=f$ (betweenness, weight, degree). This provides a basis for answering the second and third questions regarding mapping and evaluating boundary mechanisms in the physical space.

Using the data from sociometric badges, Figure 2 shows different individuals' level of engagement in brokering. Selective team-players in the bottom left quadrant are those with the lowest amount of interaction and exploration. They mainly remain inside their social network and tend to be more strategic about their inward interactions. Similar to selective team-players, proactive team players in the bottom right quadrant also conduct most of their interactions with regulars in their immediate social network, yet they seek more interactions with their fellow network members. Both selective brokers and proactive brokers in the top two quadrants tend to explore and interact with those outside their network. As opposed to selective brokers, however, proactive brokers are dedicated to connecting different disciplines and networks to one another. None of the participants in the study fell into the proactive broker category, and the majority of selective brokers had a higher degree. Interestingly, according to the matrix, proactive team-players with higher degree - larger bubbles in the bottom right quadrant - have a great potential to become proactive brokers and the majority of selective brokers have also a high degree. This confirms the workplace designers' urban life theory about the correlation between serendipitous encounters and the number and amount of interactions with different people.

Are there similarities and difference in how these three groups use the physical space? The data from location monitoring exhibited in Figure 3 revealed that, in average, selective brokers use more space than proactive team players, and proactive team players' space utilization is higher than selective team-players. Moreover, the first group's space utilization pattern is more continuous, whereas the majority of teamplayers move between one or two spots. This means explorers, with higher betweenness centrality, not only tend to travel more often and tend to use more resources in the workplace, but also, compared to team-players, they anchor in more spaces. They do not just run into people and conduct short conversations; they pause and establish meaningful ties.

Location plots also imply that the majority of brokers prefer to 'go to people' in different locations rather than host them. This is an important trait especially when it comes to learning through peripheral participation. However, interestingly, the majority of brokers were at 
$\boldsymbol{A}$

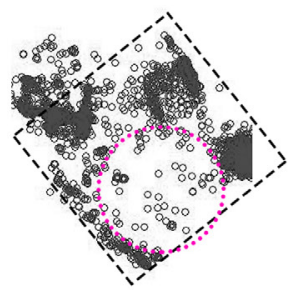

$\boldsymbol{B}$
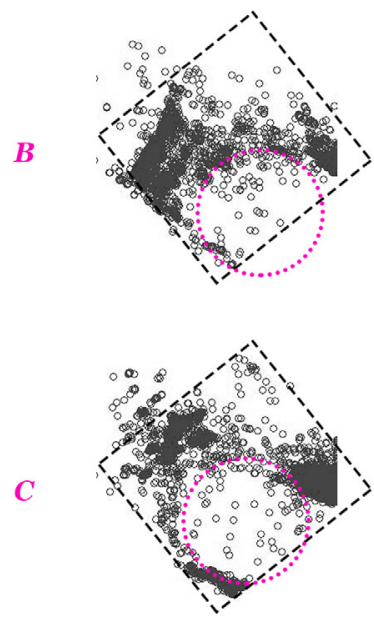
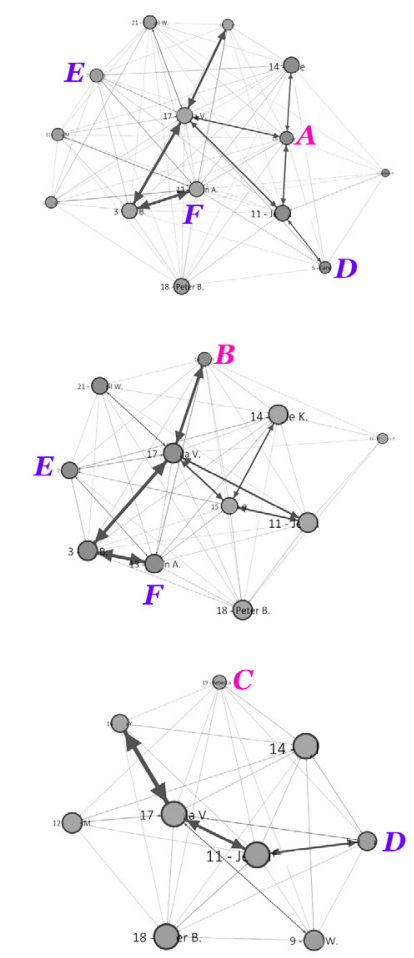

Figure 4: Individuals with complementing location plots and their social networks

the higher levels of organizational hierarchy. Another important finding was revealed when we studied a sample of participants' patterns of territorial behavior in relation to their social networks. Figure 4 shows that people whose location plots complement each other have the lowest level of interaction with one another. For example, the void in the location plots of persons $A, B$, and $C$ can be filled with the location plots of persons $D, E$, and $F$, and consequently, the individuals from the two groups rarely interact. This could be a potential problem if boundary mechanisms between the two groups could possibly result in useful and positive outcomes for the organization such as better collaboration, more innovation, better flow of information, or more effective mentoring. Recognizing the situated, transactional, and correlational relationships between the social and the spatial, the national architecture firm has decided to redesign the void along with other spaces in the workplace and launch a second research study to learn if there will be any changes in existing brokering patterns.

\section{DISCUSSION AND FUTURE DIRECTIONS}

In architectural practice, it is customary for most data gathering tools and methods to be considered as part of the Post-Occupancy Evaluation (POE) arsenal. Social and spatial analytics tools and methods are not exceptions as they help architectural programmers and designers gain insights which often cannot be captured using conventional survey methods. That said, people-space analytics, at its core, is an empathybuilding tool because it encourages end-users to participate in a
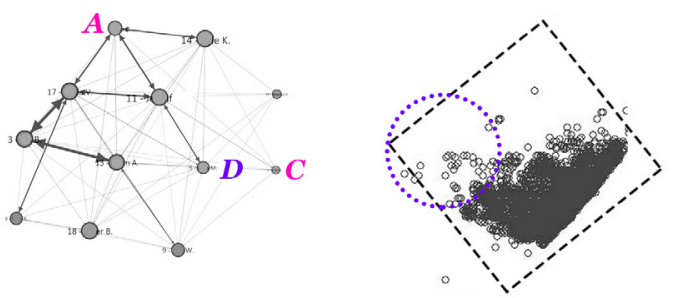

$\boldsymbol{D}$
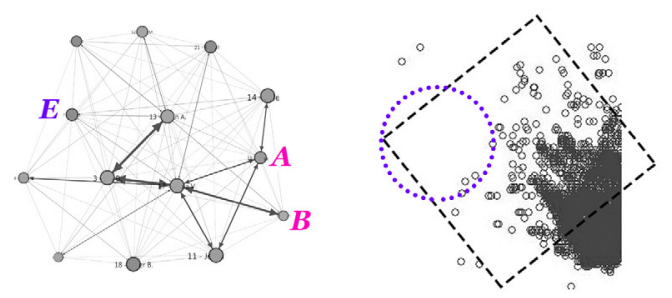

$\boldsymbol{E}$
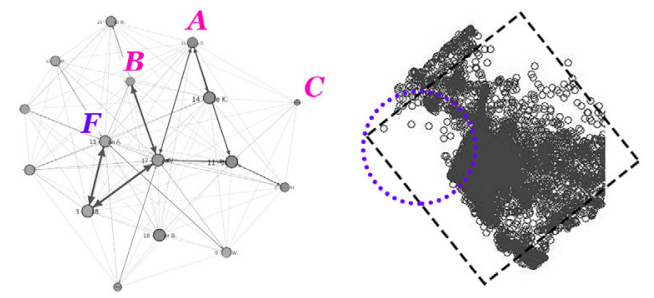

$\boldsymbol{F}$ conversation about the kind of socio-spatial patterns which support and promote organizational goals. Moreover, it provides the possibility for the organization to experiment with the use of space while mapping the impact of different spatial scenarios on important outcomes.

Finally, people-space analytics, as a combination of tools, techniques, and theories, can provide a useful framework for (1) defining, (2) mapping, and (3) understanding how social and spatial patterns relate to important outcomes in a workplace setting. A potential fourth step would be intervening in or improving those patterns being mindful of the fact that intervention in patterns goes beyond designing the physicality of the workplace and requires engaging participants in the process of changing the ways work is being conducted.

\section{ENDNOTES}

[1] Rorty, Richard. Philosophy and social hope. New York: Penguin Books, 1999.

[2] Lave, Jean and Étienne Wenger. Situated learning: Legitimate peripheral participation. Cambridge: Cambridge University Press, 1991.

[3] Wenger, Étienne, Richard McDermott, and William Snyder. Cultivating communities of practice: a guide to managing knowledge. Massachusetts: Harvard Business School Press, 2002.

[4] Wenger, Étienne. Communities of practice: Learning, meaning, and identity. Cambridge: Cambridge University Press, 1998.

[5] Wenger, Étienne. "Communities of practice: The key to knowl edge strategy." In E. L. Lesser, M. A. Fontaine, and J. A. Slusher (Eds.), Knowledge and communities. New York: Rutledge, 2000.

[6] Wenger, Étienne. "Social learning capability: four essays on innovation and learning in social systems." In Social Innovation, Sociedade e Trabalho. Booklets 12 - separate 
[7] Wenger, Étienne. "Communities of practice and social learning systems: the career of a concept." In C. Blackmore (Ed.), Social Learning Systems and communities of practice. Springer Verlag and the Open University, 2010.

[8] Lave, Jean. Cognition in practice: Mind, mathematics, and culture in everyday life. Cambridge: Cambridge University Press, 1988.

[9] Bourdieu, Pierre. Outline of a theory of practice. Cambridge: Cambridge University Press, 1977

[10] Giddens, Anthony. The construction of society: Outline of the theory of structuration. California: University of California Press, 1984.

[11] Foucault, Michel. Power/Knowledge: Selected interviews and other writings: 1972 1977, ed. by C. Gordon. New York: Pantheon, 1980.

[12] Vygotsky, Lev. "Interaction between learning and development." In M. Cole, Mind in society: The development of higher psychological processes. Cambridge, MA Harvard University Press, 1979.

[13] Brown, John S. and Paul Duguid. "Organizational learning and communities of practice: Towards a unified view of working, learning, and innovation." Organization Science, 40, no. 3, 1991.

[14] Lesser, Eric L., Michael A. Fontaine, and Jason A. Slusher. Knowledge and communities. Boston: Butterworth-Heinemann, 2000.

[15] Allee, Verna. "Knowledge networks and communities of practice." OD Practitioner: Journal of the national organization development network, 32, no. 4, 2000.

[16] Saint-Onge, Hubert and Debra Wallace. Leveraging communities of practice for strategic advantage. Boston: Butterworth-Heinemann, 2003.

[17] Koliba, Christopher and Rebecca Gajda. "Communities of Practice as an Empirical Construct: Implications for Theory and Practice." International Journal of Public Administration, 32, 2009

[18] Amin, Ash and Joanne Roberts. "Knowing in action: Beyond communities of practice." Research Policy, 38, 2008.

[19] Hughes, Jason, Nick Jewson, and Lorna Unwin. "Communities of Practice: A Contested Concept in Flux." In J. Hughes, N. Jewson and L. Unwin (Eds.), Communities of Practice: Critical Perspectives. London: Routledge, 2007.

[20] Wenger- Trayner, Étienne and Beverley Wenger- Trayner. "Learning in landscapes of practice: a framework." In E. Wenger-Trayner, M. Fenton-O'Creevy, S. Hutchinson, C. Kubiak \& B. Wenger-Trayner (Eds.), Learning in landscapes of practice: boundaries, identity, and knowledgeability in practice-based learning. New York: Routledge, 2014.

[21] Brown, John S., Allan Collins, and Paul Duguid. "Situated cognition and the culture of learning." Educational Researcher, 18, no. 1, 1989.

[22] Angie Hart, Ceri Davies, Kim Aumann, Etienne Wenger, Kay Aranda, Becky Heaver, and David Wolff. "Mobilizing knowledge in community-university partnerships: what does a community of practice approach contribute?" Contemporary Social Science: Journal of the Academy of Social Sciences, 8, no. 3, 2013.

[23] De Marsico, Maria, Carla Limongelli, Filippo Sciarrone, Andrea Sterbini, Marco Temperini. "Social Network Analysis and Evaluation of Communities of Practice of Teachers: a Case Study." In Proc. 7th Int. Workshop on Social and Personal Computing for Web-Supported Learning Communities, SPeL, for Advances in Web-Based Learning, ICW, 2014.

[24] Cross, Rob, Tim Laseter, Andrew Parker, and Guillermo Velasquez. "Using socia network analysis to improve communities of practice." California Management Review, 49 , no. $1,2006$.

[25] Pentland, Alex S. Social Physics: How Good Ideas Spread-the Lessons from a New
[26] Waber, Ben. People analytics: How sensing technology will transform business and what it tells us about the future of work. New Jersey: Pearson Education, Inc, 2013.

[27] Waber, Ben, Jennifer Magnolfi, Greg Lindsay. "Workplaces that move people." Harvard Business Review, October, 2014.

[28] Tom Kelley and Jonathan Littman. The ten faces of innovation: ideo's strategies for defeating the devil's advocate and driving creativity throughout your organization. New York: Currency/Doubleday, 2005.

[29] Freeman, Linton C. "Centrality in social networks: Conceptual clarification." Socia Networks, 1, no. 3, 1979

[30] Pentland, Alex S. "The new science of building great teams." Harvard Business Review, April, 2012

[31] Waber, Benjamin N., Daniel Olguin Olguin, Taemie Kim, and Alex (Sandy) Pentland Understanding Organizational Behavior with Wearable Sensing Technology. Academy of Management Annual Meeting. Anaheim, CA. August, 2008.

[32] Waber, Benjamin N., Daniel Olguin Olguin, Taemie Kim, and Alex (Sandy) Pentland Productivity through Coffee Breaks: Changing Social Networks by Changing Break Structure. 30th International Sunbelt Social Network Conference. Riva del Garda, Italy, July, 2010.

[33] Wu, Lynn, Benjamin N. Waber, Sinan Aral, Erik Brynjolfsson, and Alex (Sandy) Pentland. Mining Face-to-Face Interaction Networks using Sociometric Badges: Predicting Productivity in an IT Configuration Task. In Proceedings of the International Conference on Information Systems. Paris, France. December, 2008.

[34] Duffy, Frank. Work and the city. London: Black Dog Publishing Limited, 2008. 